\title{
DIE BEZIEHUNGEN DER \\ PHYSIOLOGISCHEN EIGENTHÜMLICHKEITEN DES KINDLICHEN ORGANISMUS \\ ZUR PATHOLOGIE UND THERAPIE.
}

AKADEMISCHE ANTRITTSVORLESUNG

voN

Dr. OTTO SOLTMANN,

PROF. UND MED.-RATH, DIRECTOR DER UNIVERSITÄTSKINDERKLINIK UND POLIKLINIK ZU LEIPZIG.

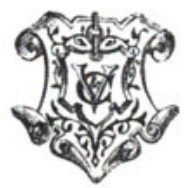

LEIPZIG, VERLAG VON VEIT \& COMP. I 895 . 
Druck von Metzger \& Wittig in Leipzig. 